This is an author-produced PDF of an article published in International Journal for Music Education. Copyright SAGE. The definitive publisher-authenticated version is available online.

The citation information of the definitive version is:

Grant, C. (2015). Learning and teaching traditional music in Cambodia: Challenges and incentives. International Journal for Music Education [Online First], pp. 1-12. DOI:

$10.1177 / 0255761415619394$

\title{
Learning and teaching traditional music in Cambodia: Challenges and incentives
}

\section{Catherine Grant ${ }^{1}$ \\ University of Newcastle / Griffith University}

Substantial efforts have been made since the Khmer Rouge regime to revitalise traditional Cambodian music genres. While they have met with some success, local circumstances still present many difficulties for the transmission of traditional music to the younger generations. This study explores the challenges in learning and teaching traditional Cambodian music, as well as incentives, from the viewpoint of a group of students, teachers and master-artists involved in the transmission activities of one NGO. Better understanding the challenges may help policy-makers, NGOs, and artists themselves to overcome them; better understanding the factors that encourage young people to learn (and older people to teach) may help safeguarding efforts at a critical juncture in the future of these art forms. Based primarily on interview and observational data from fieldwork in 2013 and 2014, the findings of this study underscore three challenges in particular to the transmission of traditional music genres in contemporary Cambodia: musical and technical difficulties, the changing social function of the genres, and economic pressures. In addition to intrinsic motivation, participants identified economic gain as a key incentive for young people to learn these genres. The author makes suggestions for overcoming the challenges and further motivating young people to learn traditional Cambodian music.

As I sit on temple grounds in a rural village near Siem Riep in northern Cambodia, the sparse tones

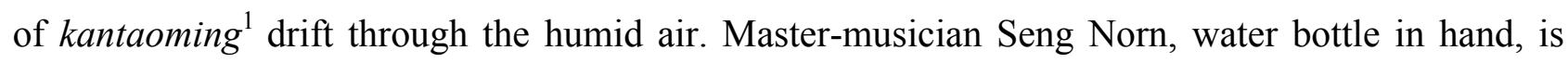
keeping a close ear on the small group of boys and young men under his tuition (Figure 1). As one of the last living masters ${ }^{2}$ of kantaoming, a funeral music genre that guides the spirit of the deceased into the afterlife, this septuagenarian is keenly aware that passing on his skills is a matter of urgency. But in contemporary Cambodia, traditional music is generally less favoured than popular genres, socioeconomic circumstances are placing significant pressures on transmission processes, and young people have limited opportunities to learn traditional music. Once the class has finished, as the monsoon clouds break overhead, I ask Master Norn whether he is optimistic

\footnotetext{
${ }^{1}$ Catherine Grant, PhD, is author of Music Endangerment: How Language Maintenance Can Help (Oxford University Press, 2014). In 2014, she received the national Australian Future Justice Medal for her research, advocacy, and community engagement relating to cultural sustainability. Catherine has been awarded an Endeavour Australia Cheung Kong Fellowship to further her research in Cambodia in 2015.
} 
about the future of kantaoming. His calm, confident smile communicated as much as his verbal response: 'I will not let it die'.

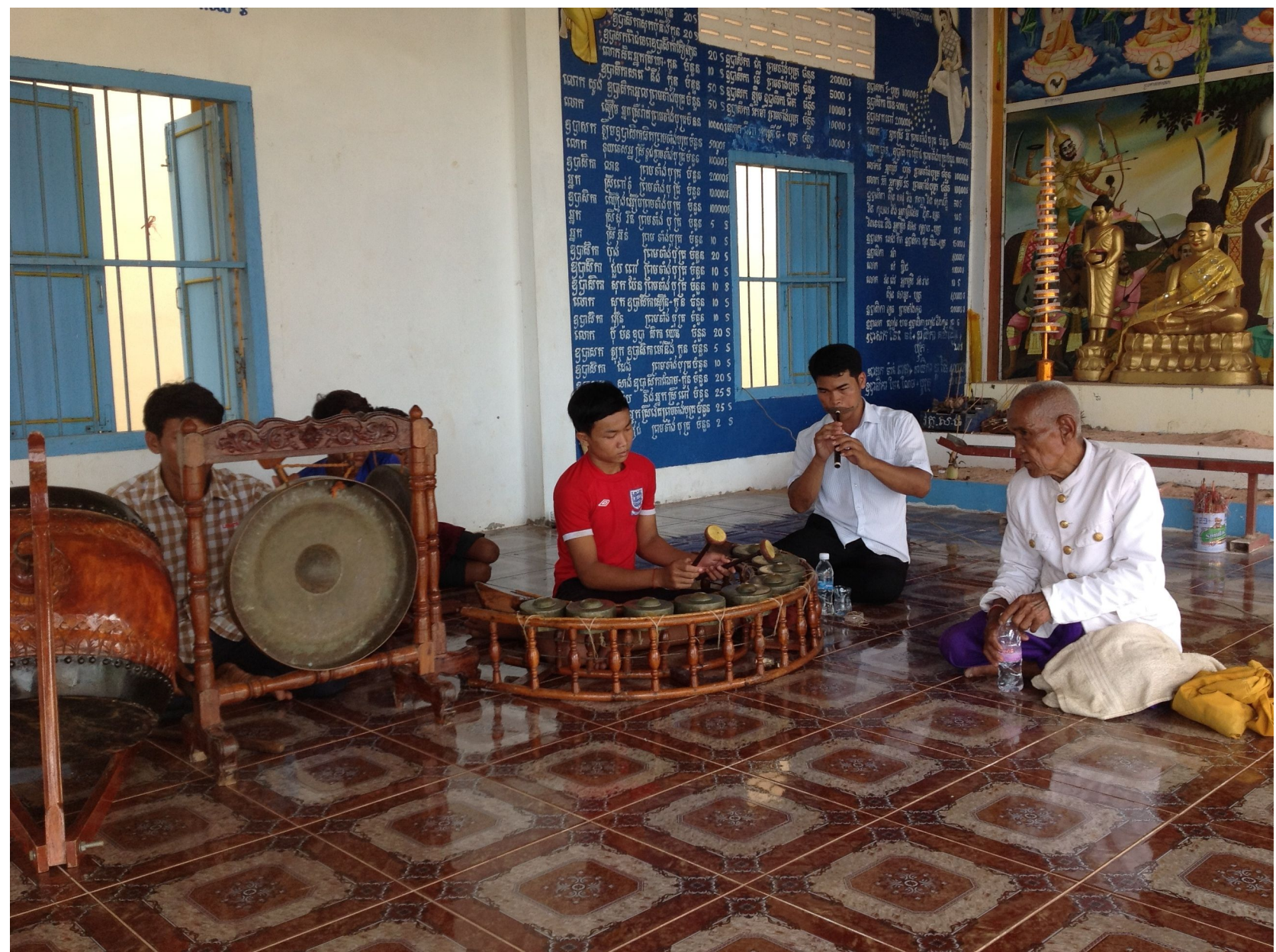

Figure 1. Master musician Seng Norn teaches kantaoming. Photo by the author, Wat Svay Thom (near Siem Reap), 6 July 2014.

\section{Learning and teaching traditional music in Cambodia}

In a forthcoming article in this journal, Kallio and Westerlund refer to a 'cultural crisis' in which the protection of Cambodian music, dance and theatre, among other cultural forms, is not only in peril from globalization, but is additionally vulnerable due to Cambodia's recent social and political history, raising questions how to safeguard an already vulnerable culture from what may be seen as an immediate, and ever increasing threat.

In the genocidal Khmer Rouge regime of the 1970s, the percentage of artists who lost their lives is estimated to be around 90\% (Sam in Sam, Roongruang, \& Nguyễn, 1998, p. 209), and the number of traditional art forms lost, perhaps 50\% (Visiting Arts, 2001, p. 13). The traditional ${ }^{3}$ genres that $^{2}$ do remain are only minimally present in the life-worlds of most Cambodian ${ }^{4}$ people: $65 \%$ of the population are under the age of 30 (UNDP, 2013), and no-one under 30 has any living memory of the pre-Khmer Rouge era, when traditional performing arts were integral to life events, rituals, and daily lives. 
Understandably, the Royal Government of Cambodia apparently does not consider itself in circumstances where it may afford to direct substantial resources towards the arts. Pressing social, political and economic challenges divert attention from efforts to foster intangible cultural heritage. Despite a fast-growing economy since the early 1990 s, $46 \%$ of the almost 15 million Cambodian people still live in 'multidimensional poverty' (UNDP, 2013). Income inequality, gender disparity, political corruption, poor legal, financial, and healthcare infrastructure, low government capacity, and a lack of basic services also present serious challenges (Um, 2011). The government professes ideological support of the arts, and has recently released its first national cultural policy, but much remains to be done before its recommendations are translated into consolidated and effective action.

Education may be added to the list of the nation's challenges. Ayres pronounces a 'crisis of education' in Cambodia (2000, p. 448). Formal education is beyond the reach of many: around $80 \%$ of the population lives rurally, and the basic costs of sending a child to early secondary school can consume around a fifth of a family's total annual income. Only around one in five Cambodians over the age of 25 have completed primary education; primary school drop-out rates are around $45 \%$ (UNDESA, 2012). The mean number of years of schooling is just 5.8 (UNDP, 2013).

Kallio and Westerlund propose that 'the extreme situation of Cambodian music education' is therefore uncomfortably positioned 'between these two crises: that of culture, and that of education' (forthcoming). Formal music education in public schools is minimal or absent altogether. The Ministry of Culture and Fine Arts, one of the poorest in the country, has been described as 'reduced to a state of helpless inertia' (Turnbull, 2006, p. 146). The Royal University of Fine Arts, including its secondary school, do provide dedicated training programs in traditional (and Western) instruments, but students usually need some musical ability in order to be accepted. Traditional systems of transmission within families, pagodas, and villages are still present to some degree (Sam, 2007), but have dwindled in the post-Khmer Rouge era. For these reasons, opportunities for young Cambodians to learn and experience traditional music, so far as they exist, often come through avenues other than formal schooling or traditional (pre-Khmer Rouge) transmission mechanisms (Kallio \& Partti, 2013).

Since the early 1990s, charitable non-government organisations (NGOs) have become a particularly important provider of arts and cultural education in Cambodia. Many cultural NGOs combine the aim of providing arts education (especially to youth) with that of cultural revitalisation. Examples abound: Apsara Arts Association aims to contribute to education and poverty reduction through the arts; Kampot Traditional Music School and Champey Academy of Arts both provide music and dance training to vulnerable and disadvantaged children; and Amrita Arts fosters artistic innovations based on traditional arts. With substantial support from foreign philanthropists, organisations like these play a key role in developing knowledge of the traditional performing arts 
in younger generations. They are also helping to explore contemporary contexts for traditional genres, such as festivals or school-based performances, in a social environment where some traditional arts have lost their 'original' function or context (as discussed later in this paper).

Internationally, the most well known cultural NGO in Cambodia is Cambodian Living Arts (CLA), founded in the late 1990s by Khmer Rouge survivor Arn Chorn-Pond (www.cambodianlivingarts.org). Employing almost exclusively Cambodian staff, CLA financially supports master-artists to pass on their skills, provides arts training, runs cultural 'tours' to promote traditional arts to visitors, and advocates for the arts and culture within the country and abroad. Its performing arts classes reach several hundred students across a number of provinces, and its vibrant performance schedule, 'Plae Pakaa', generates employment and performance opportunities and bolsters awareness of Cambodian traditional arts locally and internationally.

Inevitably, the heavy reliance on NGOs for educating young people in the arts and culture of Cambodia carries problems and risks. Ear (2007) believes that as a postconflict state, Cambodia has had 'no choice but to accept aid', and is thus 'a forced experiment in aid dependence. The experiment has shown . . . that foreign aid has a number of unintended consequences in postconflict environments' (p.10). One question is whether long term, reliance on foreign funds for cultural activities will 'benefit the performing arts and artists or create a dependence that lessens their own initiative and local audience interaction' (Diamond, 2003, p. 147); another is whether foreign support is much more than 'thumbs in the dyke when it comes to restoring a thousand years of culture' (Turnbull 2006, p. 148). Further concerns are the tendency towards 'a neocolonialist edge on the art that's created' (Hodal, 2012), or in the educational context, 'who learns what, and why' (Kallio \& Partti, 2013, p. 15). For NGO-led music education programs, these issues are complex, and a deeper examination of them is beyond the scope of this paper. With the likelihood that many Cambodian children would be lacking arts education at all without these NGOs, for the moment, they promise to be one, even if not the ideal, solution to the 'cultural crisis' facing Cambodia.

\section{Approach and methods}

This research explores the experiences and perspectives of teachers and students involved with the music education programs of NGO Cambodian Living Arts (CLA). It reports on observational and interview data collected on two month-long field trips in February 2013 and June-July 2014. My research on the 2013 trip explored the vitality and viability of traditional Cambodian music genres (reported in Grant, 2014b). One key theme emerging from that research was the importance of contemporary transmission practices and approaches in the vitality and viability of traditional music. The extensive data on this theme alone warranted further consideration, and in the iterative process typical of qualitative research, those findings from my 2013 fieldwork generated questions 
that I then raised with the same interview participants, and others, on my subsequent visit around 16 months later. Inductive thematic analysis (Boyatzis, 1998) was carried out a second time on all data, generating the themes presented in the remainder of this paper.

Purposeful sampling (Creswell, 2003) was used to recruit interviewees. In total, I conducted 20 semi-structured interviews (Kvale, 1996) with master-musicians, teachers, and students currently or recently involved with the transmission programs of CLA. Interviews lasted between 20 and 60 minutes. Ten interviews took place in the CLA offices in Phnom Penh; the remainder, in rural villages in the provinces of Kampong Speu and Takeo in Cambodia's south, Siem Reap in the north, and Battambong in the north-west. These interviews took place either at the village homes of interviewees or in the grounds of the school or pagoda where they taught or learnt music. I worked with the assistance of a local qualified interpreter. Like Kallio and Westerlund (forthcoming), I acknowledge the limitations of working through interpretation, but given the dearth of scholarship on Cambodian music education, I feel this is a defensible transgression. Immediate interpretation enabled immediate clarification and checking. Participation was secured via informed consent; all participants gave permission for their interviews to be audio-recorded and later transcribed.

On my trips, I also formally or informally interviewed many others in relation to my research, including government cultural officials, university music lecturers, and teachers and management personnel at several music- and education-related NGOs (apart from CLA). Using a combination of video recording and a field diary to document my observations, I attended dozens of rehearsals, performances, individual lessons and group classes, both affiliated with CLA and not. I took a series of traditional-instrument lessons myself, in order to better understand transmission processes and settings; and participated in several of CLA's earlier-mentioned 'cultural tours', ranging from one to seven hours in length. These experiences inform this paper.

Two overarching themes emerged from data analysis. The first is the challenges and impediments students and teachers reported in teaching and learning traditional music; the second relates to incentives and motivation for teaching and learning. The following discussion of these themes should be understood in the specific context of the NGO in question. However, participants often also refer to their experiences as students and teachers at the Royal University of Fine Arts (and occasionally in other contexts), which may have happened prior to or alongside their involvement with CLA.

\section{Challenges and impediments}

Participants primarily spoke of three main challenges to learning and teaching traditional music: the technical and musical difficulties inherent in the genres; challenges relating to social and cultural considerations; and economic pressures. 


\section{Musical and technical}

For many participants in this research, the musical and technical difficulties of Cambodian traditional genres pose a significant challenge to learning. Several interviewees felt this extended so far as acting as a disincentive for students to learn.

Pich Sarath, teacher of chapei dong weng ${ }^{5}$ ('long-necked lute') reported that only 5 students of the 25 in his first-year class at the School of Fine Arts graduated after the six years of study. He attributes the high attrition rate to students' uncertainty at whether they possess the required ability, as well as their realisation of the degree of dedication and commitment needed to become proficient. During his own years of chapei study, Pich himself confided in his master that was unsure he had sufficient ability to learn (to which his master simply responded, 'That's ok, you can just keep trying') (pers.int., 21 Feb 2013). Like Pich, Keot Ran reported frustration and doubt on the part of her students in their experience of learning: 'some of them get a bit frustrated with themselves after they learn for a while, and they would like to follow me but they can't' (pers.int., $22 \mathrm{Feb}, 2013)$. Keot teaches $\operatorname{smot}^{6}$, Buddhist chanting associated with healing and cremation ceremonies, and she agrees that the genre is not easy to learn - especially the texts, which are usually in Pali (the language of Theravada Buddhism) and rarely understood by either performers or listeners. Sok Duch, master-musician of pleng kar boran ${ }^{6}$ (classical wedding music) and UNESCOdesignated Living Human Treasure, also reported a gap between his efforts to teach and his students' learning:

I was asked by the Ministry of Fine Arts and Culture: Why didn't I teach them to become like

me, to be talented like me? And I cannot answer that question, because people have different talents. . . . I wanted to [pass on my talent], but I cannot. (pers.int., 22 Feb 2013)

Sok added that some of his pleng kar boran students were slow to memorise pieces: 'When I teach them the new songs, they forget the old ones they've just done'. Student Iem Vichet focuses on learning pinn peat (the most well-known traditional genre and ensemble in Cambodia, used in a range of ceremonial contexts) because he finds it easier to memorise than other genres: 'I cannot learn other forms because I cannot really remember well' (pers.int., 11 Feb 2013).

These concerns about the musical and technical difficulties involved in learning traditional Cambodian genres raise the question of why - or indeed whether - these challenges present a greater obstacle to transmission in contemporary Cambodia than in earlier times. On this matter, participants felt that although the intrinsic difficulties of the genres have not grown since the preKhmer Rouge era, in contemporary Cambodia they pose greater challenges to learning. Reasons for this are manifold, and related to the significant changes in transmission mechanisms explored later in this paper. Many music learners also study at school or university, or work to earn a living, impinging on the time they can devote to learning music. Thus, opportunities for dedicated and 
extended learning are rare. Even where the traditional master-apprentice system does still operate, typically in rural villages, 'discipline while studying tend[s] to be more relaxed than in ancient times' (Keo, 2005, p. 36).

Arguably, these contemporary challenges are offset to at least some degree by certain innovations in learning and teaching, including the use of technology and the development of notation systems (Keo, 2005). Tro sau (fiddle) player Phan Chamroeun (in his 20s) believes these tools facilitate his learning; when he was young, he learnt only by ear, 'but now because we have technology, I also study by listening to the mp3 audio and musical notation' (pers.int., 21 Feb 2013). Multi-instrumentalist Yim Chanty, in her mid-40s, recently 'learnt to play musical notation [and] I'm very proud of myself, because it's not an easy thing to do' (pers.int., 21 Feb 2013). In mid-2014, the members of the Community of Living Chapey, a breakaway group from CLA comprising around a dozen players ranging in age from late teens to their $30 \mathrm{~s}$, began learning Western notation. They hope this will expedite learning, as well as help standardise the improvised solo repertoire so that the group can play as an ensemble. Some of the masters are cautious about such activities, however; Sok Duch warns, notation 'might be a guide but does not give you an exact picture' (pers.int., 22 Feb 2013).

\section{Social and cultural}

In relation to the role of social and cultural challenges in the transmission of traditional music, participants spoke of the encroachment of 'outside' culture on Cambodian traditional genres, and the loss of social contexts and functions for these genres.

Several interviewees claimed that the lure and immediate appeal of Western music and culture, and to a lesser extent Cambodian popular music, has lessened young Cambodians' interest in learning traditional music. Unsurprisingly, it was teachers and masters, more than students, who expressed concern at this situation. UNESCO claims that it presents a risk for the sustainability of traditional music: masters are struggling to find keen learners 'because young people prefer something new or modern' (2013, p. 31). Drew McDowell, manager of the NGO Music Arts School in Phnom Penh, reports 'far less' interest in traditional Cambodian instruments than Western ones only about 10 students out of around 200 learnt a traditional instrument, despite tuition fees being set 50\% lower (pers.comm., 2 July, 2014). Man Men, pleng kar boran ${ }^{7}$ master, feels that recently, 'outsider' interest in traditional Cambodian music has in some ways been even stronger than that shown by Cambodians themselves (pers.int., 11 Feb 2013).

Another concern is the loss of social contexts and functions for traditional genres. Sam (2007) notes that the shortening of the traditional wedding ceremony from seven days and nights 'in the olden days' to just one day and night nowadays - a change he attributes to economic pressures has been one cause of the atrophy of pleng kar boran. With the exception of the provinces of Siem 
Riep and Takeo and among certain populations in Phnom Penh, this genre has been supplanted by modern wedding music (Man Men, pers.int., 11 Feb 2013). Regards the snaeng (buffalo horn), Yim Chot attributes limited interest among learners to the instrument's traditional use in ceremony, including wild elephant hunts: nowadays Cambodian people would have little cause to play this instrument in their everyday lives (pers.int., 21 Feb 2013).

It is not always the loss of traditional functions or constructs that presents challenges for transmission: paradoxically, sometimes their continued strength plays a role. Seng Norn reported that community members disallowed him to teach the funeral genre kantaoming within earshot of the village, because of its association with death (pers.int., 11 Feb 2013). Agreeing that it was important to find an appropriate location for his classes, he moved further away to the bachar of the village pagoda, where a body is kept before burial. That solution brought its own problems: when a funeral ceremony was underway, no class could be conducted. A similar problem arose for Srey Theoung, whose kantaoming classes at another pagoda were sometimes displaced by ceremonies; he also found that younger children, afraid of the bachar, were reluctant to attend classes. Both problems were resolved when the principal of the local primary school agreed that classes could be held there (pers.int., 5 July 2014). Another example of constructs presenting a challenge to transmission is the common belief that playing the chapei causes blindness, a superstition that continues to be a considerable disincentive for young people to learn it (Pich Sarath, pers.int., 21 Feb 2013).

\section{Economic}

Economic circumstances impede transmission processes and practices in various ways. First, financial circumstances make it difficult for students to devote time to their learning. In 2013, Pich Sarath taught around 10 chapei students ranging in age from late teens to around 40 years old, 'but most of them are poor people, and sometimes they study for a while and then they need to stop for work and then they come back' (pers.int., Feb 2013). According to Seng Norn, school study takes lot of his students' time, and household responsibilities much of the remainder: 'Some parents have another job for [students] to do when they are free. . . they go to the rice field to carry the corn and harvest something ... It seems like there is a lot for them to do. They have duties in the family, in the school, so they don't have enough free time to join the class' (pers.int., 11 Feb 2013). Students themselves also spoke of these pressures.

Second, economic pressures may inhibit access to instruments. Masters Seng Norn and Sok Duch both spoke of the poor state of repair of some of their instruments; Seng added that the single set of kantaoming instruments in his village inadequately allowed for the demands of teaching and performance $^{8}$ (pers.ints, 11 Feb 2013). When I met him in 2013, Sok was trying to minimise instrument-making costs through resourcefulness; pointing to a pile of dry bones a few feet away 
during our interview in front of his home, he told me that that was his old cow, and he was using her to make parts of his instruments. Metallic instruments like the gongs of the kantaoming ensemble are harder to self-manufacture. In another way, though, economic hardship may act in favour of transmission of traditional genres. Kem Rithy, teacher of sralai (quadruple reed oboe) at the Royal University of Fine Arts (with no affiliation to CLA), observed a general trend in the Faculty of Music for wealthier students to study Western music and poorer ones to study traditional music: only the wealthier students have the means to purchase Western instruments for their study (pers.int., 3 July 2014).

In the late 1990s, Sam-Ang Sam wrote that 'many old Khmer musicians have given up playing music since the rewards are meagre, and they have had to choose more lucrative professions to support their families, which naturally take precedence over the preservation of traditions' (Sam in Sam, Roongruang, \& Nguyễn, 1998, p. 210). This remains true today. Most artists earn less than the minimum wage for factory workers (Hodal, 2012, estimates US\$50 per month). Pich Sarath is one example, teaching and performing but working outside of the music sector too: 'I don't think I can make a living only on chapei' (pers.int., 21 Feb, 2013). It is little wonder that many young people seek more lucrative forms of employment; those who do earn from their art are compelled to supplement that with other sources of income.

\section{Motivation and incentives}

With these challenges and impediments to learning and teaching traditional music in Cambodia, why do students learn at all? Why do teachers teach? Interviewees primarily framed these issues in terms of intrinsic motivation and economic gain.

Both teachers and students felt that self-motivation is an important factor in students' learning. Keot Ran felt that most of her students are driven to learn smot 'from their own passion', rather than that of their parents or others (pers.int., 22 Feb 2013). Intrinsic motivation also inspires teachers' efforts to teach: in his late 80 s, Sok Duch reported that he was still teaching because 'I want my student to be perfect at what he or she is doing. . I'm still trying hard to make sure that what I teach them is with them very clearly, and they are perfect in their skill' (pers.int., 22 Feb 2013).

Given the apparent shortage of interest in traditional music among youth, one question that arises is how intrinsic motivation is generated, particularly in students. Exposure within the family is one likely factor. Yim Chanty believes that although the khloy (bamboo flute) is one of the more popular instruments for young Cambodians to learn, 'The only person who would choose that as their career is somebody who has a father ${ }^{9}$ who plays it' (pers.int., 21 Feb 2013). Both Yim and Phan Chamroeun grew up with traditional music in the home, learning from their fathers (pers.ints., 
21 Feb 2013). Seng Norn's grandson Pong Pon learns kantaoming in order to pass on the skills and knowledge of his grandfather; Sok Duch's grandson Lun Chumnith plays kse diev to continue his grandfather's legacy; both a son and daughter of pleng kar boran master Man Men teach traditional music; and one of the most promising young smot students under Keot Ran's tuition is her own 14year-old grandson.

Although an impediment for learners in ways described above, economic hardship is also a motivating factor for students to learn traditional music. While CLA continues to provide scholarships to promising students, some years ago it provided every student a small stipend to support them through their studies. Pich studied chapei at a time when students received \$US8 a month,

and eight dollars a month at that time was quite a lot of money. That was 2003. And then I just kept going, because I thought I could learn and then get some money as a motivation and encouragement at the same time. And when I could play a little bit, I played near my house, and all the people started coming to see what I was doing, and I became proud of myself that I could play. (pers.int., 21 Feb 2013)

Sok Duch reported that the discontinuation of CLA's stipend scheme was one reason for a drop of almost $50 \%$ in the number of students in his pleng kar boran class (seven at the time of our interview; 22 Feb 2013).

Yim Chanty believes that economic considerations are a decisive factor in young people's choice of which instrument to learn: prospective learners 'will choose a skill that gives them more job opportunities', like the popular khloy (flute) (pers.int., 21 Feb 2013). Moving from the provinces to Phnom Penh upon graduating from high school in the hope of finding a job that could subsidise his university studies, Pich Sarath reasoned, 'it's rare to have chapei players, so if I pick up that skill, in the future it might be better for me' (pers.int., 21 Feb 2013). He hopes that his newly established chapei troupe might generate income for its members, as well as sustainable opportunities for performing, teaching and learning (pers.int., 29 June, 2014). Pinn peat and kantaoming teacher Srey Theoung believes that the prospect of making some money from their skills is the leading incentive for his students, ranging from 10 to 22 years old, to attend lessons every Sunday (pers.int., 5 July 2014). Some entrepreneurial youngsters combine their musical ability and skills with business acumen, like 23-year-old Phoeun Sreypov. Despite smot not easily lending itself to popular promotion, her growing small business (www.sreypovsmot.com) revolves around the genre; she performs regularly, has featured on local TV, and has sung on tour in the USA several times (pers.int, 27 June 2014). Conversely, the lack of a performance market may be one reason for the unpopularity of instruments like the snaeng (buffalo horn) (Yim Chanty, pers.int., 21 Feb 2013). 


\section{Conclusion}

In Cambodia, undertaking to learn or teach traditional music is not only a matter of education, aesthetic pleasure, strengthening individual and collective identities, or even investing in skills capacity and economic gain. It is all of these things. But teaching and learning activities are arguably also the decisive factor in whether traditional music genres will endure through future generations of Cambodians as living, changing, vibrant, responsive cultural practices - or fall silent in the next decade or two, as the skilled masters pass away. The risk is real:

Despite the efforts of Cambodian Living Arts and other NGOs to preserve traditional popular culture, there is a question mark over its long-term survival. There is a real risk that music in the folk tradition . . . will be preserved as quaint relics or the subject for foreign ethnomusicologists rather than being, as once was the case, an integral part of the community's life. (Osborne, 2008, p. 209)

Time is of the essence, with many of master-musicians now in their seventies and eighties, and many not in good health. On my 2014 field trip, two masters were too ill to attend our scheduled interview, and another, apologising for his feebleness, reported he had been recently discharged from the local hospital.

This research identified three key areas presenting challenges to the transmission of traditional music genres in Cambodia: the technical and musical; the social and cultural; and the economic. The first appears to result less from the intrinsic degree of difficulty of the genres (which remains the same as in the pre-Khmer Rouge era) than from shifts in modes of learning and teaching that leave young people little time to devote to their practice. Innovations in teaching and learning, such as the use of recordings and notation as aides-memoires, hold promise to mitigate these difficulties for young learners, to some degree. As they increase in popularity and use, these tools will almost certainly have an impact on the traditions themselves, perhaps particularly in terms of reducing their improvisatory nature and standardising the repertoire (Sam, 2007). The extent to which their effects are acceptable will be an important consideration for the Cambodian community of performers, masters, teachers and learners in the immediate future.

The second challenge, relating to the social and cultural contexts of traditional music, is bound up with the changing socioeconomic circumstances of $21^{\text {st }}$ century Cambodia. Precedent from other situations of endangerment indicates that an attitude of responsive flexibility and a willingness to explore new contexts and functions optimises the chances of securing a sustainable future for 'old' genres (Grant, 2014a). Again, it will be up to the culture-bearers themselves to decide the extent to which innovation and repositioning is acceptable or desirable. The negative constructs surrounding certain genres (such as the connection in the popular imagination between the chapei and blindness) will also need to be addressed, through awareness-raising and education. 
The third challenge to transmission of traditional music - the economic pressures on teachers and learners - is also a function of the nation's socioeconomic situation. Poverty is ubiquitous. The flip side is that these same economic circumstances represent a major incentive for students to learn and teachers to teach. For this reason, NGOs, government, and other stakeholders might do well to invest in opportunities for poverty alleviation and income generation through the arts. In the context of cultural revitalisation in Cambodia, however, a circular conundrum potentially manifests: music transmission initiatives may generate employment and income, thus alleviating poverty; but income generation and economic development itself can lead to abandonment of traditional cultural practices (Grant, 2014a). Applied ethnomusicology, particularly research on the use of music and the arts in conflict transformation efforts (e.g. Pettan, 2010) and on the connections between poverty and music (e.g. Harrison, 2013), provide theoretical frameworks for further research on this topic, which is strongly indicated.

These three sets of challenges are best interpreted in the context of a wider set of factors interplaying with the sustainability of traditional music in Cambodia. Some of these arose as points of discussion in this paper, including the relative paucity of concrete government support for the arts and arts education, and the manifold transmission activities of non-profit cultural NGOs. Others were only implicitly addressed, such as the tension between contemporary national concerns of growth and innovation versus efforts to preserve the nation's intangible cultural heritage. As Kallio and Westerlund astutely observe, this tension intensifies in relation to music education concerns, which represents one crucial point where these two issues collide: 'The need to respond to demands of globalization, regionalization and individualization, as identified by national curriculum reforms in Cambodia, "may well be in conflict" (Sam 2008, p. 94) with the need for preservation of ancient cultural traditions and heritage' (forthcoming). As music educators, we might consider our own position on these issues, as well as our potential to support the sustainable future of music traditions 'under threat', from Cambodia or elsewhere in the world. Activities to this end could take the form of engaging with diasporic communities through our teaching, advocating for school education about the music of minority and Indigenous communities, and/or fostering an understanding among our students about the importance and value of cultural diversity, among others.

Without much doubt, the dearth of school-based music education in Cambodia is a significant impediment to a vibrant traditional-music culture. Sam (2007, p. 128) and others have advocated for the inclusion of arts programs in the public school curriculum. However, for as long as Cambodia's attention is directed to more pressing political, social and economic issues, it seems unlikely that children will have access to a quality arts education as an integral part of their schooling. For this reason, cultural NGOs, their importance heightened by the nation's 'weak and precarious' 
performing arts infrastructure (Turnbull, 2006, p. 148), seem set to continue to play a paradoxically equivocal and critical role in the future of traditional Cambodian genres.

The same is true of Cambodian diasporic communities, particularly in the USA, Canada, France and Australia. Many of their population left their homeland as refugees, the daily struggles of war or poverty supplanted with other kinds of challenges (including post-traumatic stress disorder). Sam reports that the situation of traditional music in expatriate populations is 'even worse' than within Cambodia: 'Among them, Khmer traditional music loses its audience, its full range of repertoire, instrumentation, and performance and becomes virtually symbolic' (2007, p. 126). By contrast, other researchers propose that the continued practice of the arts in these communities has served to maintain 'a time-lagged Cambodian culture abroad, a culture that is better preserved in many respects than in the homeland, thus frozen in time and divorced from the realities of both homeland and adopted home' (Winter \& Ollier, 2006, p. 14). Examining diasporic experiences of teaching and learning traditional Cambodian music is beyond the scope of this study, but research on the topic would help elucidate how these communities may help ensure the sustainable futures of these genres, both outside of Cambodia and within it.

This paper opened with an anecdote of one master's optimism about the future of his art. The next decade or two will determine whether such optimism is warranted. Indications for the future of traditional Cambodian music are both promising and grim, depending on angle and attitude. What is certain is that overcoming the barriers to learning and teaching traditional music, and capitalising on factors that motivate teachers and learners, will be crucial to the success of transmission initiatives, and indeed the very viability of these genres.

\section{Acknowledgements}

Thank you to the students, teachers, and master-artists who participated in this study; to Keo Darasith, Sun Sopheak, and Sothea at Phare Ponleu Slepak for interpreting and project assistance; to Jeff Dyer for helpful feedback on a draft of this article; and to Yon Sokhorn and all the team at Cambodian Living Arts for administrative support. This research was funded in part by a 2013 Travelling Fellowship awarded to the author by the Australian Academy of the Humanities.

\section{Notes}

${ }^{1}$ Also kontoaming, kantoam ming or korng skor. English transliterations of instrument and genre names are variable in spelling. For more on Cambodian instruments and genres, see Sam, Roongruang and Nguyễn (1998), UNESCO (2003) and Keo (2005).

${ }^{2}$ Throughout this article, in keeping with local practices, the term master is reserved for those artist-teachers who learnt and practiced their art in the pre- Khmer Rouge era. 
${ }^{3}$ Traditional is a highly contested term. In this paper, I use it to refer to pre-Khmer Rouge era 'heritage' genres, without implying that these genres pre- and post-Khmer Rouge are, or should be, identical. In 1998, Sam, Roongruang and Nguyễn wrote of a 'fundamental division' between traditional and modern music in Cambodia (pp. 155-156). This division is arguably still clear, even though Cambodian artists are increasingly exploring 'convergences and collisions' between genres and cultures.

${ }^{4}$ Although the term Khmer has historically referred to the dominant ethnic group in Cambodia (and the language of that group), nowadays, it is sometimes to refer to all peoples of Cambodia, including ethnic minorities. In this paper, I use the term Cambodian, though the specific genres mentioned by participants are from the dominant ethnic group. Most cultural maintenance efforts support the majority Khmer group, which makes up over $90 \%$ of the population (Kallio \& Parti, 2013).

${ }^{5}$ Also chapey dang veng. Used in ensembles and in chrieng chapei, 'epic singing'.

${ }^{6}$ Also smaut.

${ }^{7}$ Also pleng kar buran or vung phleng kar.

${ }^{8}$ In the months following, I led a crowdfunding campaign to fund a full ensemble of kantaoming instruments, delivered to Seng in late 2013 (http://pozi.be/lastlivingmaster)

${ }^{9}$ For reasons beyond the scope of this paper to explore, traditional music in Cambodia is generally learnt and performed by boys and men more than girls and women. CLA are actively encouraging female learners in their transmission programs.

\section{References}

Ayres, D.M. (2000) Tradition, modernity, and the development of education in Cambodia. Comparative Education Review, 44(4), 440-463.

Boyatzis, R.E. (1998). Transforming qualitative information: Thematic analysis and code development. Thousand Oaks, London, and New Delhi: SAGE.

Creswell, J. (2003). Research design: Qualitative, quantitative, and mixed methods approaches. Thousand Oaks, CA: SAGE.

Diamond, C. (2003). Emptying the sea by the bucketful: The dilemma in Cambodian theatre. Asian Theatre Journal, 20(2), 147-178.

Ear, S. (2007). Aid Dependence in Cambodia: How Foreign Assistance Undermines Democracy. New York: Colombia University Press.

Grant, C. (2014a). Music Endangerment: How Language Maintenance Can Help. New York: Oxford University Press.

Grant, C. (2014b). Perspectives of culture-bearers on the vitality, viability and value of traditional 
Khmer music genres in contemporary Cambodia. The Asia-Pacific Journal of Anthropology 15(1), 26-46. doi: 10.1080/14442213.2013.866685.

Harrison, K. (Ed.) (2013). ICTM Yearbook for Traditional Music, 45. Special edition: Music and poverty. Ljubljana, Slovenia: ICTM.

Hodal, K. (2012, Mar 29). The art of survival. The Guardian. Retrieved from Proquest.

Kallio, A. \& Partti, H. (2013). Music education for a nation: Teaching patriotic ideas and ideals in global societies. Action, Criticism, and Theory for Music Education 12 (3), 5-30.

Kallio, A.A. \& Westerlund, H. (forthcoming). The ethics of survival: Teaching the traditional arts to disadvantaged children in post-conflict Cambodia. International Journal of Music Education: Research.

Keo Narom (2005). Cambodian Music. Phnom Penh: Reyum.

Kvale, S. (1996). InterViews: An introduction to qualitative research interviewing. Thousand Oaks, CA: SAGE.

Osborne, M. (2008). Phnom Penh: A cultural history. New York: Oxford University Press.

Pettan, S. (2010). Applied ethnomusicology: Bridging research and action. Music and Arts in Action 2(2): 90-93. Retrieved from

www.musicandartsinaction.net/index.php/maia/article/view/ethnomusicology/44

Sam, S. (2007). Transmission of Khmer traditional performing arts: Its genuineness, challenge, and impact on society. In Y. Terada (Ed.), Authenticity and Cultural Identity: Senri Ethnological Reports 65: 123-136.

Sam, S.-A., Roongruang, Panya \& Nguyễn, Phong T. (1998). The Khmer people. In Miller, Terry (Ed.), Garland Encyclopedia of World Music Vol. 4: Southeast Asia. Retrieved from Alexander Street database.

Turnbull, Robert (2006). A burned-out theater: The state of Cambodia's performing arts. In Ollier, Leakthina Chau-Pech \& Winter, Tim (Eds) (2006). Expressions of Cambodia: The politics of tradition, identity, and change, 133-149. Abingdon, Oxon: Routledge.

Um, Khatharya. (2011). Cambodia: Hopes, trials, and tribulations. Southeast Asian Affairs (2011), 53-70.

UNDESA (2012). International Human Development Indicators: Cambodia. Retrieved from http:/hdrstats.undp.org/en/countries/profiles/KHM.html

UNDP [United Nations Development Programme] (2013). About Cambodia. Retrieved from http://www.kh.undp.org/content/cambodia/en/home/countryinfo/

UNESCO (2003). Traditional musical instruments of Cambodia ( $2^{\text {nd }}$ ed.). Retrieved from unesdoc.unesco.org/images/0013/001352/135257mb.pdf

UNESCO (2013). Cambodia: Intangible Cultural Heritage [website]. Retrieved from 
http://www.unesco.org/culture/ich/en/state/kh

Visiting Arts (2001). South East Asia Regional Arts Profile: Cambodia Arts Directory. London: Visiting Arts.

Winter, T. \& Ollier, L.C-P. (2006). Introduction: Cambodia and the politics of tradition, identity and change. In Ollier, Leakthina Chau-Pech \& Winter, Tim (Eds) (2006). Expressions of Cambodia: The politics of tradition, identity, and change, 1-19. Abingdon, Oxon: Routledge. 